\title{
Phlorizin from sweet tea inhibits the progress of esophageal cancer by antagonizing the JAK2/STAT3 signaling pathway
}

\author{
ZHENXIAN JIA $^{1,2}$, YUNING XIE ${ }^{1}$, HONGJIAO WU ${ }^{2}$, ZHUO WANG $^{3}$, ANG LI $^{1}$, ZE LI ${ }^{1}$, \\ ZHENBANG YANG ${ }^{4}, \mathrm{ZHI}_{\mathrm{ZHANG}}{ }^{5}, \mathrm{ZHAOBIN} \mathrm{XING}^{2}$ and XUEMEI ZHANG ${ }^{1,2}$ \\ ${ }^{1}$ School of Public Health; ${ }^{2}$ College of Life Science; Schools of ${ }^{3}$ Pharmacy and ${ }^{4}$ Basic Medical Sciences, \\ North China University of Science and Technology, Tangshan, Hebei 063210; ${ }^{5}$ Department of Oncology, \\ Affiliated Tangshan Gongren Hospital, North China University of Science and Technology, \\ Tangshan, Hebei 063000, P.R. China
}

Received May 30, 2020; Accepted April 15, 2021

DOI: $10.3892 /$ or.2021.8088

\begin{abstract}
Phlorizin, an important member of the dihydrochalcone family, has been widely used as a Chinese Traditional Medicine for treatment of numerous diseases. The present study aimed to investigate the potential therapeutic effects of phlorizin on esophageal cancer. Phlorizin, extracted from sweet tea, was used to treat esophageal cancer cells. Cell proliferation, migration and invasion were determined using Cell Counting Kit- 8 and colony formation assays, and wound healing and Transwell assays, respectively. RNA sequencing and bioinformatics analysis was used to investigate the potential mechanism of phlorizin in the development of esophageal cancer. Fluorescent staining and flow cytometry was used to measure the level of apoptosis. The expression level of the proteins, P62/SQSTM1 and LC3 I/II, and the effect of phlorizin on the JAK2/STAT3 signaling pathway was detected using western blot analysis. The results demonstrated that phlorizin could inhibit cell proliferation, migration and invasion. Bioinformatics analysis showed that phlorizin might be involved in pleiotropic effects, such as the 'JAK/STAT signaling pathway' (hsa04630), 'MAPK signaling pathway'(hsa04010) and 'apoptosis' (hsa04210). It was also confirmed that phlorizin promoted apoptosis and inhibited autophagy in the esophageal cancer cells. Notably, phlorizin might inhibit the proteins in the JAK/STAT signaling pathway, which would affect cancer cells. Taken together, the present data showed that phlorizin inhibited the progression of esophageal cancer by antagonizing the JAK2/STAT3 signaling pathway.
\end{abstract}

Correspondence to: Professor Xuemei Zhang or Professor Zhaobin Xing, College of Life Science, North China University of Science and Technology, 21 Bohai Avenue, Tangshan, Hebei 063210, P.R. China

E-mail: zhangxuemei@ncst.edu.cn

E-mail: xingzb@ncst.edu.cn

Abbreviations: CCK-8, Cell Counting Kit-8; RNA-Seq, RNA sequencing; GO, Gene Ontology; KEGG, Kyoto Encyclopedia of Genes and Genomes

Key words: sweet tea, phlorizin, JAK2, STAT3, esophageal cancer

\section{Introduction}

Epidemiological investigations have shown that esophageal cancer is one of the most common malignant tumors of the digestive tract in the world (1-3). Its incidence and mortality rates rank 7th and 6th among all malignant tumors worldwide according to global cancer statistics in 2018 (4). In recent years, neoadjuvant therapy $(5,6)$, minimally invasive surgery $(7,8)$ and modern precision radiotherapy (9) for the treatments of esophageal cancer have improved survival times; however, the overall efficacy is still not high, with a 5-year survival rate of $18 \%$ based on cases diagnosed between 2005 and 2011 in North America (10). Natural products are important resources for anticancer drugs $(11,12)$, such as gypenoside $L$ and matrine. Studies have demonstrated that gypenoside L inhibited the proliferation of esophageal cancer cells and enhanced the sensitivity of them to chemotherapy (13), and matrine increased the inhibition rate of cell proliferation by inducing cell autophagy (14). Therefore, there is an urgent requirement to develop natural medicine with high efficiency and minimal side effects to improve the treatment of esophageal cancer and improve population health.

The perennial shrub, Lithocarpus polystachyus Rehd, commonly known as 'sweet tea' in Chinese folk, is often used as a source of sweets and traditional oriental medicine (15). Previous studies have shown that the aqueous extract from the leaf of sweet tea inhibited breast cancer proliferation and improved blood sugar status (16). Phlorizin (phloretin 2'-O-glucoside), the main component of sweet tea, is an important member of the dihydrochalcone family. Previous studies confirmed that phlorizin was the main phenolic glucoside in the Malus species (17) and was one of the sodium-linked glucose transporter inhibitors (18). A series of bioactive functions of phlorizin have been discovered, such as lowering blood sugar levels and improving memory, and having anti-oxidative and anti-cancer properties (19-22).

The aim of the present study was to investigate the therapeutic effects of phlorizin on esophageal cancer using transcriptome sequencing and functional experiments, to provide experimental evidence to develop phlorizin-based anticancer foods or drugs. 


\section{Materials and methods}

Phlorizin extraction. Sweet tea leaves were collected from woodland in Bama county in Guangxi, China. The fresh sweet tea leaves were dried, sieved and immersed in an ethanol solution. The mixture was then extracted using ultrasonic extraction $(40 \mathrm{kHz}$ for $20 \mathrm{~min}$ at room temperature) and vacuum filtration, concentrated by rotary evaporation to remove the ethanol, then freeze-dried to obtain a crude product. Subsequently, $5 \mathrm{~g}$ crude extract was added to water and dissolved in a treated macroporous resin column for $30 \mathrm{~min}$. The column was washed with deionized water to remove impurities, then the phlorizin was washed with $75 \%$ ethanol. The solution was eluted to produce the eluate. The concentrated eluate was removed from the ethanol and placed in a zero-degree environment to recrystallize. The crystallized product was further filtered to obtain a dry powder, which is a dry saponin monomer of phlorizin (Fig. 1).

Determination of the phlorizin content of the dry powder. The purity of the dry powder (a dry saponin monomer of phlorizin) was determined using a Waters ACQUITY ultra performance liquid chromatography $\mathrm{H}$-Class system (Waters Corporation), equipped with an ACQUITY UPLC BEH $\mathrm{C}_{18}$ $(1.7 \mu \mathrm{m} ; 2.1 \times 50 \mathrm{~mm}$; Waters Corporation) analytical column coupled with a column filter and the column temperature was kept at $30^{\circ} \mathrm{C}$. The mobile phase consisted of water (A) and acetonitrile (B) in a maintained ratio (73:27), with a flow rate of $0.2 \mathrm{ml} / \mathrm{min}$. The injection volume of the sample was $10 \mu \mathrm{l}$ and the detection wavelength was set at $285 \mathrm{~nm}$. A total of $10.00 \mathrm{mg}$ phlorizin standard (Beijing Century Aoke Biotechnology Co., Ltd.) was weighed, diluted with $10 \mathrm{ml}$ methanol and completely dissolved to obtain the internal standard. The purity of the dry saponin monomer of phlorizin was at least $95 \%$.

Cell culture and treatments. The human KYSE450 and KYSE30 cell lines were kindly gifted from Dr Y. Shimada from the First Department of Surgery, Hyogo College of Medicine (Hyogo, Japan). Both the cell lines were then cultivated in RPMI-1640 medium (Thermo Fisher Scientific, Inc.) supplemented with 10\% FBS (Thermo Fisher Scientific, Inc.), $100 \mu \mathrm{g} / \mathrm{ml}$ streptomycin and $100 \mathrm{U} / \mathrm{ml}$ penicillin (Beijing Solarbio Science and Technology Co., Ltd.) at $37^{\circ} \mathrm{C}$ in a humidified incubator with $5 \% \mathrm{CO}_{2}$. The cells were seeded in cell culture plates overnight in complete medium, then treated with various concentrations $(0,0.05,0.10,0.20,0.40,0.80 \mathrm{a}$ nd $1.60 \mathrm{mM}$ ) of phlorizin dissolved in dimethyl sulfoxide (DMSO; final concentration $<0.1 \%$; Sigma-Aldrich; Merck $\mathrm{KGaA})$.

Cell viability assay. The Cell Counting Kit-8 (CCK-8; Dojindo Molecular Technologies, Inc.) assay was utilized to detect the viability of the cells. A total of $5 \times 10^{3}$ cells were seeded into each well of a 96-well plate, then incubated with phlorizin at different concentrations. At 24,48 or 72 h, $10 \%$ CCK-8 solution was added to the cells and incubated for another $2 \mathrm{~h}$. The optical density was measured at $450 \mathrm{~nm}$ using a microplate reader (Tecan Group). The proliferation of the cells, treated with phlorizin, was normalized to the control cells. The $50 \%$

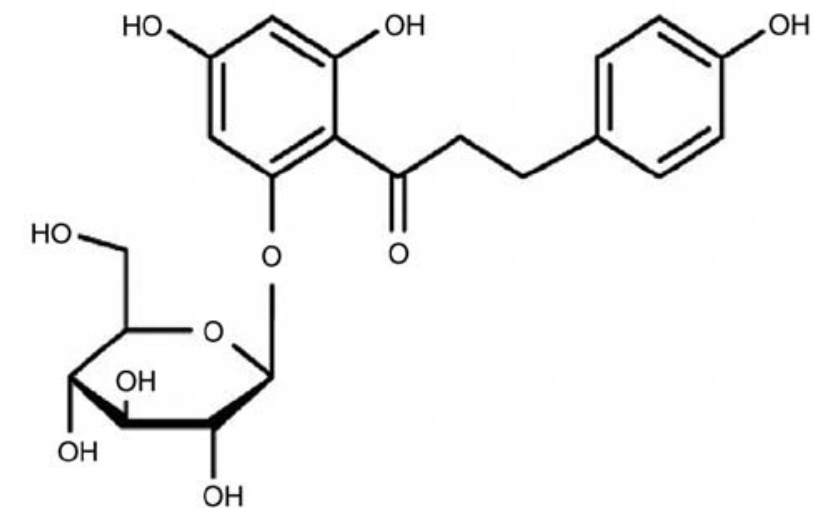

Figure 1. Chemical structure of phlorizin.

inhibitory concentration $\left(\mathrm{IC}_{50}\right)$ in the two cell lines was calculated using SPSS v23.0 (IBM Corporation).

Colony forming assay. The cells ( $3 \times 10^{5}$ cells/well) were seeded in 6-well plates to $80 \%$ confluency. After treated with phlorizin at 0.20 or $0.80 \mathrm{mM}$ for $24 \mathrm{~h}$, the cells $\left(2 \times 10^{3}\right.$ cells $\left./ 3 \mathrm{ml}\right)$ were digested with $0.25 \%$ trypsin (Thermo Fisher Scientific, Inc.) and seeded into a $30 \mathrm{~mm}$ culture dish for 14 days. Cells without the treatment of phlorizin served as a control. After fixing with $4 \%$ paraformaldehyde, for $15 \mathrm{~min}$ at room temperature, followed by $0.1 \%$ crystal violet staining for $30 \mathrm{~min}$ at room temperature, washing with PBS and air-drying, the colonies were detected using an IX71 inverted fluorescent microscope (Olympus Corporation), at x40 magnification.

Wound healing assay. Wound healing assay was used to determine cell migration. The esophageal cancer cells (KYSE450 and KYSE30) were seeded ( $3 \times 10^{5}$ cells/well) in a 6 -well plate and cultured at $37^{\circ} \mathrm{C}$ in a humidified incubator with $5 \% \mathrm{CO}_{2}$. When the cell monolayer was $100 \%$ confluent, the cells were scraped with a sterile $200 \mu$ l pipette tip, then washed 3 times with PBS to remove the cell debris. Subsequently, the cells were treated with phlorizin $(0.00,0.20$ and $0.80 \mathrm{mM})$ for $0,24,48$ and $72 \mathrm{~h}$. Images of the wound gap were captured using an IX71 fluorescent microscope (magnification, x40; Olympus Corporation) at $0,24,48$ and $72 \mathrm{~h}$ after scratching. The distance between the edges of the wound was then measured using ImageJ software (v1.42q; National Institutes of Health).

Transwell assay. Transwell chambers $(8-\mu \mathrm{m})$ coated with or without Matrigel (incubated at $37^{\circ} \mathrm{C}$ for $5 \mathrm{~h}$ ) (Corning, Inc.) were used to determine the cell migratory and invasive abilities of the cells. In brief, the esophageal cancer cells $\left(3 \times 10^{5}\right.$ cells/well) were seeded in 6 -well plates overnight and treated with phlorizin $(0.00,0.20$ and $0.80 \mathrm{mM})$ for $24 \mathrm{~h}$. Subsequently, the cells $\left(1.5 \times 10^{5}\right.$ cells $\left./ 200 \mu 1\right)$ were added to the upper chamber with serum-free RPMI-1640 medium and incubated at $37^{\circ} \mathrm{C}$ in a humidified incubator with $5 \% \mathrm{CO}_{2}$ for $24 \mathrm{~h}$. The non-migratory and non-invasive cells were then washed away with a cotton swab. The migrated or invaded cells in the lower chamber, which were incubated with complete medium, were fixed with $4 \%$ paraformaldehyde and stained with $0.1 \%$ crystal violet, both for $30 \mathrm{~min}$ at room 
temperature. An inverted fluorescent microscope (Olympus Corporation) was used to count the invasive or migratory cells at $\mathrm{x} 200$ magnification.

RNA sequencing (RNA-Seq). TRIzol ${ }^{\circledR}$ (Invitrogen; Thermo Fisher Scientific, Inc.) was used to extract total RNA from the KYSE450 cells with or without $0.5 \mathrm{mM}$ phlorizin for $48 \mathrm{~h}$, in accordance with manufacturer's instructions. A NanoPhotometer spectrophotometer (Implen $\mathrm{GmbH}$ ) was used to measure RNA purity. RNA integrity was assessed using the RNA Nano 6000 Assay kit and the Bioanalyzer 2100 system (Agilent Technologies, Inc.). RNA-Seq libraries were constructed using the NEB Next Ultra RNA Library Prep kit for Illumina (cat. no. E7420L; New England Biolabs, Inc.). The concentration of the RNA library was measured using a Qubit $^{\circledR}$ RNA Assay kit and a Qubit ${ }^{\circledR}$ 2.0 Flurometer (Thermo Fisher Scientific, Inc.) then the RNA was diluted to $1 \mathrm{ng} / \mu \mathrm{l}$. Poly-T oligo-attached magnetic beads were used to enrich the RNA with a polyA tail for cDNA synthesis. Subsequently, cDNA was ligated to a cBot Cluster Generation System using TruSeq PE Cluster Kit v3-cBot-HS (cat. no. PE-401-3001; Illumia, Inc.). The libraries were then sequenced on an Illumina Hiseq 4000 platform (Illumina, Inc.) to generate 150 bp paired-end reads. RNA-Seq and data collection was performed by Beijing Biomics Biotech Co., Ltd.

Data preprocessing. Raw data in the FASTQ format were firstly processed using in-house perl scripts (v5.32.1; Perl Foundation). Briefly, clean data was obtained by removing reads containing adapter, ploy- $\mathrm{N}$ and low-quality reads from the raw data. Clean and trimmed FASTQ reads were aligned to the human hg19 genome using TopHat (v2.0.12) (23). Cufflinks (v2.1.1) (24) was used to assemble the mapped reads of each sample. Fragments per kilobase of transcript per million mapped reads was used to determine the transcription abundance of each gene.

Biological function and pathway enrichment analyses. The edgeR package (v3.26.8) from Bioconductor in R language (http://www.bioconductor.org/) was used to identify differentially expressed genes (DEGs) with the fold change of $>2$ and the false discovery rate of $<0.01$. Gene Ontology (GO) and Kyoto Encyclopedia of Genes and Genomes (KEGG) pathway enrichment analyses were performed to identify the potential enriched biological functions of the DEGs. KEGG Orthology Based Annotation System v2.0 software (http://kobas.cbi.pku. edu.cn) was used to performed statistical enrichment analysis of the DEGs in the GO and KEGG pathways. Q-value $<0.05$ was set as the cut-off for selecting the significantly enriched GO terms and KEGG pathways.

Hoechst and annexin V staining. Hoechst33342 staining was used to observe the nuclear morphology of the apoptotic cells. The esophageal cancer cells (KYSE450 and KYSE30) were seeded $\left(3 \times 10^{5}\right.$ cells/well) in a 6 -well plate and cultured at $37^{\circ} \mathrm{C}$ in a humidified incubator with $5 \% \mathrm{CO}_{2}$ overnight prior to phlorizin treatment $(0.00,0.20$ and $0.80 \mathrm{mM})$. After $48 \mathrm{~h}$, the cells were washed with PBS and fixed with $4 \%$ paraformaldehyde for $15 \mathrm{~min}$ at room temperature, followed by staining with $3 \mu \mathrm{g} / \mathrm{ml}$ Hoechst33342 solution (Beijing Solarbio Science and Technology Co., Ltd.) for $10 \mathrm{~min}$ at room temperature in the dark. The stained cells were then washed with PBS and observed using an IX71 fluorescent microscope at x400 magnification (Olympus Corporation).

Annexin $\mathrm{V}$ staining was used to detect apoptotic cells using live cells. The KYSE450 and KYSE30 cells were seeded $\left(3.0 \times 10^{5}\right.$ cells/well $)$ in 6 -well plates and cultured at $37^{\circ} \mathrm{C}$ in a humidified incubator with $5 \% \mathrm{CO}_{2}$ overnight. Subsequently, the cells were treated with $0.1 \%$ DMSO or phlorizin $(0.20$ or $0.80 \mathrm{mM})$ for $48 \mathrm{~h}$. After washing with PBS, the cells were labeled with an Annexin V-FITC/PI apoptosis detection kit (BD Biosciences) and were visualized using an IX71 fluorescent microscope (magnification, x100; Olympus Corporation).

Flow cytometry analysis. Flow cytometry analysis was also used for a cellular apoptosis assay. Following 48 h-treatment of phlorizin, the cell pellets were harvested and resuspended in $500 \mu \mathrm{l}$ binding buffer supplemented with $5 \mu \mathrm{l}$ Annexin V-FITC and $5 \mu \mathrm{l}$ PI (BD Biosciences) for $20 \mathrm{~min}$ in dark, then detected using a flow cytometer (CytoFlex; Beckman Coulter, Inc.). The percentage of apoptotic cells was analyzed using FlowJo software (v10.0.7; Tree Star, Inc.).

Western blot analysis. The KYSE450 and KYSE30 esophageal cancer cells were treated with phlorizin $(0.00,0.20$ and $0.80 \mathrm{mM})$ for $48 \mathrm{~h}$, then lysed using RIPA buffer (Thermo Fisher Scientific, Inc.). The supernatant containing the total protein, was collected by centrifugation at $14,000 \mathrm{x} \mathrm{g}$ at $4^{\circ} \mathrm{C}$ for $17 \mathrm{~min}$, then the concentration of the total protein was detected using a BCA kit (Beijing Solarbio Science and Technology Co., Ltd). Either a 10 or $12 \%$ SDS-PAGE (80 $\mu \mathrm{g}$ protein loaded per lane) was used to separate the different proteins. Subsequently, the proteins were transferred to nitrocellulose membranes. After blocking for 50 min with 5\% skimmed milk in TBS with $0.05 \%$ Tween-20 at room temperature, the membranes were incubated with the primary antibody overnight at $4^{\circ} \mathrm{C}$, then washed and incubated with HRP-conjugated secondary antibodies for $30 \mathrm{~min}$ at $37^{\circ} \mathrm{C}$. The target proteins were then visualized using an ECL kit (GE Healthcare) and an E-Gel imager (Universal Hood II; Bio-Rad Laboratories, Inc.), then analyzed using ImageJ software (v1.42q; National Institutes of Health). $\beta$-actin was used as the control. The following primary antibodies were used: Anti-P62/SQSTM1 (1:10,000 dilution; cat. no. ab109012; Abcam), anti-phosphorylated(p)-JAK2 (1:5,000 dilution; cat. no. ab32101; Abcam), anti-p-STAT3 (1:5,000 dilution; cat. no. ab68153; Abcam), anti-JAK2 (1:5,000 dilution; cat. no. ab108596; Abcam), anti-STAT3 (1:5,000 dilution; cat. no. ab76315; Abcam), anti- $\beta$-actin (1:2,000 dilution; cat. no. 60008-1-lg; Proteintech Group, Inc.) and anti-LC3B (1:2,000 dilution; cat. no. 2775; Cell Signaling Technology, Inc.). The following secondary antibodies were used: Goat anti-mouse IgG (1:5,000 dilution; cat. no. S0002; Affinity Biosciences Co., Ltd), goat anti-rabbit IgG (1:5,000; cat. no. ZB-2301; OriGene Technologies, Inc.).

Monodansylcadaverine (MDC) staining. Cell autophagy was investigated using a MDC assay kit (Beijing Solarbio Science and Technology Co., Ltd). The esophageal cancer cells were 
harvested and adjusted to a density of $1 \times 10^{6}$ cells $/ \mathrm{ml}$. The cell suspension was stained with MDC stain for $20 \mathrm{~min}$ at room temperature and resuspended in collection buffer according to the manufacturer's instructions. The cell suspension was dropped onto a slide, then covered with the cover slip. Cell autophagy was determined using an IX71 inverted fluorescent microscope (magnification, x100; Olympus Corporation).

Statistical analysis. SPSS v23.0 (IBM Corporation) and GraphPad Prism v7.0 (GraphPad Software, Inc.) were used for data analysis. The data was presented as the mean \pm SEM. To analyze the differences among groups, either an unpaired Student's t-test or one-way ANOVA was used with Dunnett's post hoc test. $\mathrm{P}<0.05$ (two-sided) was considered to indicate a statistically significant difference.

\section{Results}

Phlorizin inhibits cell viability in human esophageal cancer cells. A CCK-8 assay was used to determine the effect of phlorizin on esophageal cancer cell viability. The results showed that phlorizin inhibited the proliferation of esophageal cancer cells (KYSE450 and KYSE30) in a time- and dose-dependent manner (Fig. 2A and B). This inhibitory effect was also confirmed by colony formation experiments (Fig. 2C-F).

Phlorizin modulates esophageal cancer migration and invasion in vitro. To further validate the effect of phlorizin on tumor migration and invasion, the aforementioned cells were treated with phlorizin, at different concentrations and observed at different time points. Wound healing assay showed a marked decrease in the edge closure speed of the wound in phlorizin-treated cells, indicating the inhibition of phlorizin on the migration of esophageal cells (Fig. 3A-D). The results from a Transwell assay further supported this result (Fig. 3E and F). To determine the cell invasive ability, a Matrigel assay was used. As illustrated in Fig. 3G and H, the number of invaded cancer cells in the lower chamber was significantly reduced by the addition of phlorizin. Taken together, these results indicated that phlorizin had a significant effect on the migration and invasion of esophageal cancer cells.

DEG identification and functional annotation. To identify the genes regulated by phlorizin in esophageal cancer cells, DEGs were identified using RNA-Seq. There were 749 upregulated genes and 1,405 downregulated genes in the KYSE450 cells treated with phlorizin compared with that in the control (Fig. 4A and B). Furthermore, the autophagy marker gene, P62/SQSTM1 had high expression levels, which was of interest (Fig. 4B). In addition, GO was used to analyze the biological functions of the DEGs, including three aspects of biology: Biological processes, cellular components, and molecular function. The top $20 \mathrm{GO}$ terms of the DEGs were primarily involved in biological processes and molecular functions (Fig. 5A). KEGG pathway analysis showed that the DEGs were significantly enriched in 'TNF signaling pathway' (hsa04668),

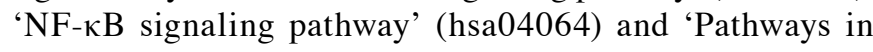
cancer' (hsa05200) (Fig. 5B). According to the number of DEGs, the top 5 KEGG pathways included 'pathways in cancer' (hsa05200), 'MAPK signaling pathway' (hsa04010),
'HTLV-1 infection' (hsa05166), 'Cytokine-cytokine receptor interaction' (hsa04060) and 'PI3K/AKT signaling pathway' (hsa04151) (Fig. 5C). With respect to the KEGG classification, most of the DEGs were involved in environmental information possessing and human diseases (Fig. 5C).

Phlorizin induces the apoptosis of esophageal cancer cells. As the KEGG pathway analysis showed that the DEGs were significantly enriched in apoptosis-related pathways, apoptosis analysis was performed. Hoechst33342 staining showed that the KYSE30 and KYSE450 cells treated with phlorizin had notable apoptosis characteristics, such as chromatin condensation and nuclear fragmentation (Fig. 6A and B). Consistently, Annexin V/PI staining showed that phlorizin increased the number of apoptotic cells (Fig. 6C and D). In addition, flow cytometry analysis showed that there were more early and total apoptotic cells in esophageal cancer cells treated with phlorizin compared with that in the control (Fig. 6E). Notably, the high concentration of phlorizin $(0.80 \mathrm{mM})$ resulted in more apoptotic cells compared with that in cells treated with $0.20 \mathrm{mM}$ phlorizin.

Phlorizin inhibits autophagy of esophageal cancer cells. As aforementioned, phlorizin increased the mRNA expression level of P62/SQSTM1 (Fig. 4B) and the DEGs were significantly enriched in the 'MAPK signaling pathway' (Fig. 5C) in esophageal cancer cells. It is well-known that the MAPK signaling pathway $(25,26)$ and P62/SQSTM1 (27-29) play an important role in autophagy. Therefore, the effect of phlorizin on autophagy in the esophageal cancer cells was investigated.

The cells treated with increasing concentration of phlorizin showed an increased protein expression level of P62/SQSTM1 and decreased protein expression level of LC3II (Fig. 7A-D). As the critical indicators of autophagic flux, the changes in the protein expression level of P62/SQSTM1 and LC3II suggested that phlorizin could be involved in cell autophagy.

In addition, MDC is a selective fluorescent marker for autophagic vacuoles. The MDC staining results are presented in Fig. 7E-G and showed that compared with that in the control group, the cells treated with phlorizin showed an increased number of autophagic cells in a dose-dependent manner.

Phlorizin inhibits the expression of the proteins in the JAK/STAT signaling pathway in esophageal cancer cells. Bioinformatics analysis showed that phlorizin was significantly enriched in the JAK2/STAT3 pathway in the KYSE450 cells (Fig. 5C). The JAK2/STAT3 signaling pathway has a regulatory effect on esophageal cancer growth, metastasis and apoptosis (30-32). To determine whether phlorizin was involved in JAK2 and STAT3 activation, the expression levels of the proteins involved in the JAK2-STAT3 signaling pathway were analyzed using western blot analysis. The results demonstrated that phlorizin not only inhibited the phosphorylation of JAK2 and STAT3, but also the expression of total JAK2 and STAT3 protein. Notably, phlorizin exhibited greater JAK2/STAT3 signal antagonism at high concentrations (Fig. 8A-F). These findings indicated that phlorizin may have a positive therapeutic effect on esophageal cancer by antagonizing JAK2/STAT3 signal transduction. 
A

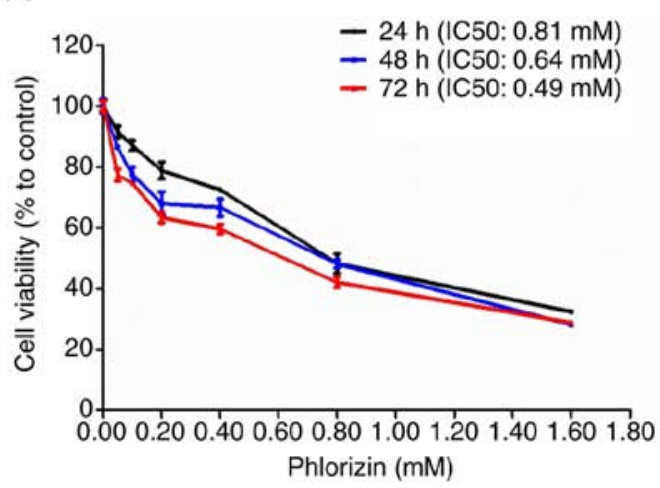

C

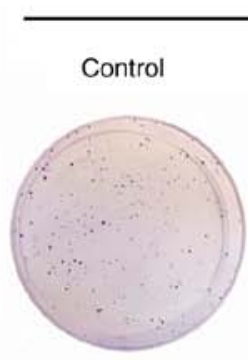

KYSE450

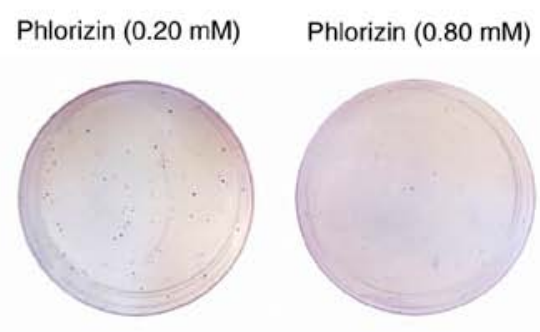

E

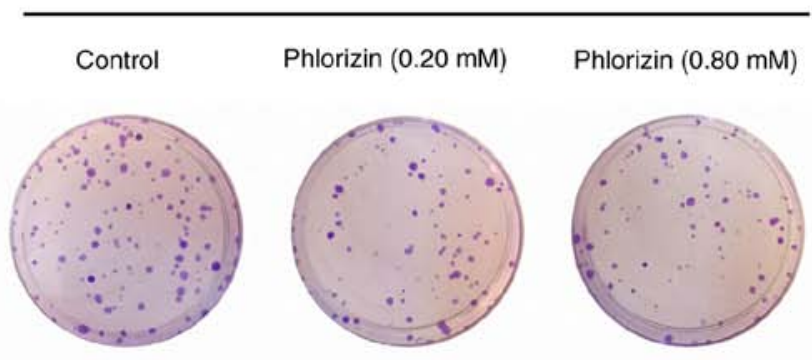

B
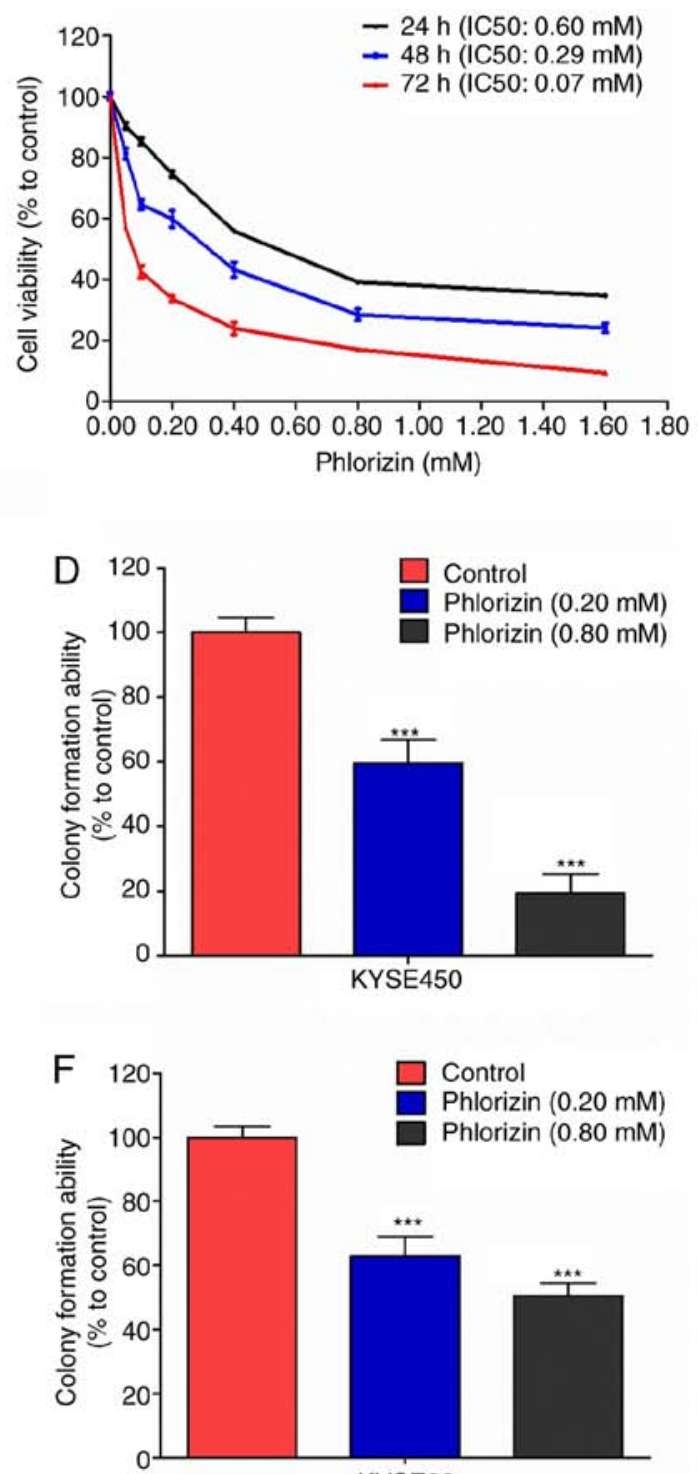

Figure 2. Cell viability analysis of esophageal cancer cells treated with phlorizin. (A) KYSE450 and (B) KYSE30 cells were treated with different concentration of phlorizin for 24, 48 and $72 \mathrm{~h}$, then cell viability was measured using a Cell Counting Kit-8 assay. Images of the (C) KYSE450 and (E) KYSE30 cells from the colony forming assay and the results were subsequently (D and F) quantitatively analyzed. IC ${ }_{50}$ was calculated for each group using SPSS. The results are from 3 independent experiments and normalized to the control. ${ }^{* * *} \mathrm{P}<0.001$.

\section{Discussion}

In recent years, numerous available natural plant-derived agents, with low toxicity, have been identified to be effective in treating cancer by suppressing the proliferation of cells $(33,34)$. Cancer cells exist in a complex environment; therefore, the underlying mechanisms of how these natural plant-derived agents are involved in pro-apoptosis, anti-autophagy and anti-proliferation of cancer cells is still unknown.

Phlorizin is the main component of the Chinese Traditional Medicine 'sweet tea', which can be used to prevent and treat esophageal cancer by drinking it daily. According to the results of the present study, by suppressing esophageal cancer cell proliferation, migration and invasion, phlorizin might serve as an effective esophageal cancer cell inhibitor in vitro. The concentration of phlorizin used in the present study was in-line with previous studies, in other types of cancer $(35,36)$. In the present study, more efforts were made to determine the signaling pathway that phlorizin could affect. GO and KEGG pathway analyses showed that the DEGs were enriched in apoptosis and autophagy-related pathways. The detection of apoptosis and autophagy, using different methods, further verified this prediction. Autophagy and cell apoptosis, which represent type II and I programmed cell death respectively, have been associated with tumor genesis and progression (37-40). The present study showed that phlorizin induced apoptosis and antagonized autophagy of the esophageal cancer cells. LC3 and P62/SQSTM1, the pivotal proteins of autophagy, participate in the formation and clearance of the autophagosome (41-44). Physiologically, soluble LC3-I is present in the cytoplasm. When autophagy occurs, LC3-I can be converted to LC3-II by processing 

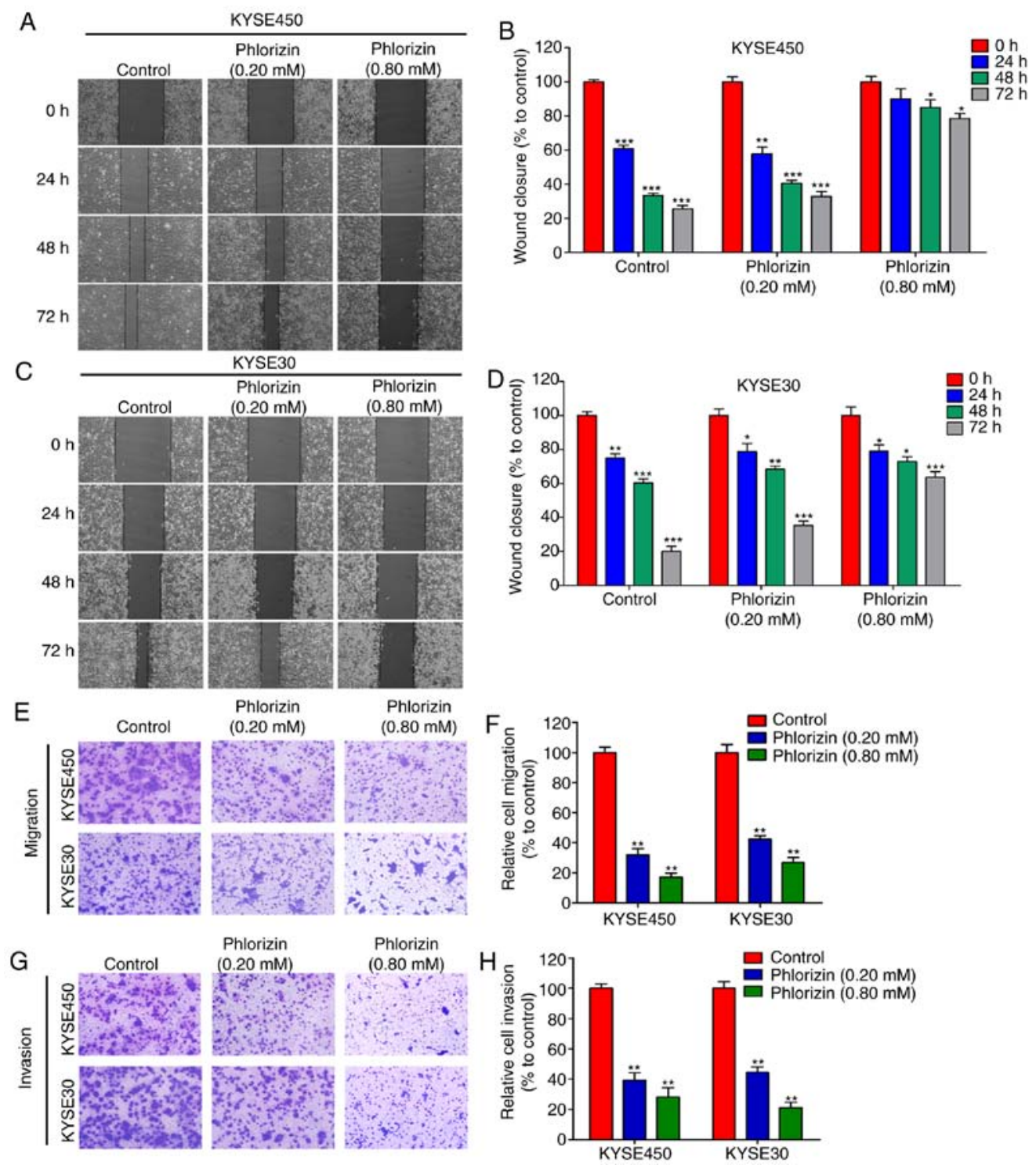

Figure 3. Cell migratory and invasive abilities of phlorizin-treated esophageal cancer cells. (A) Wound healing assay was performed following treatment of the KYSE450 cells with phlorizin and images were captured at 0,24, 48 and $72 \mathrm{~h}$ later, and the results were (B) statistically analyzed. Magnification, x40. (C) Wound healing assay was performed following treatment of the KYSE30 cells with phlorizin and images were captured at 0, 24, 48 and 72 h later, and the results were (D) statistically analyzed. Magnification, x40. (E) Cell migration was determined using a Transwell assay following treatment of the KYSE450 and KYSE30 cells with phlorizin and the results were (F) statistically analyzed. Magnification, x200. (G) Cell invasion was evaluated using a Matrigel assay following treatment of the KYSE450 and KYSE30 cells with phlorizin and the results were (H) statistically analyzed. Magnification, x200. The results are from 3 independent experiments and normalized to the control. ${ }^{*} \mathrm{P}<0.05,{ }^{* * *} \mathrm{P}<0.01,{ }^{* * * *} \mathrm{P}<0.001$ vs. control.
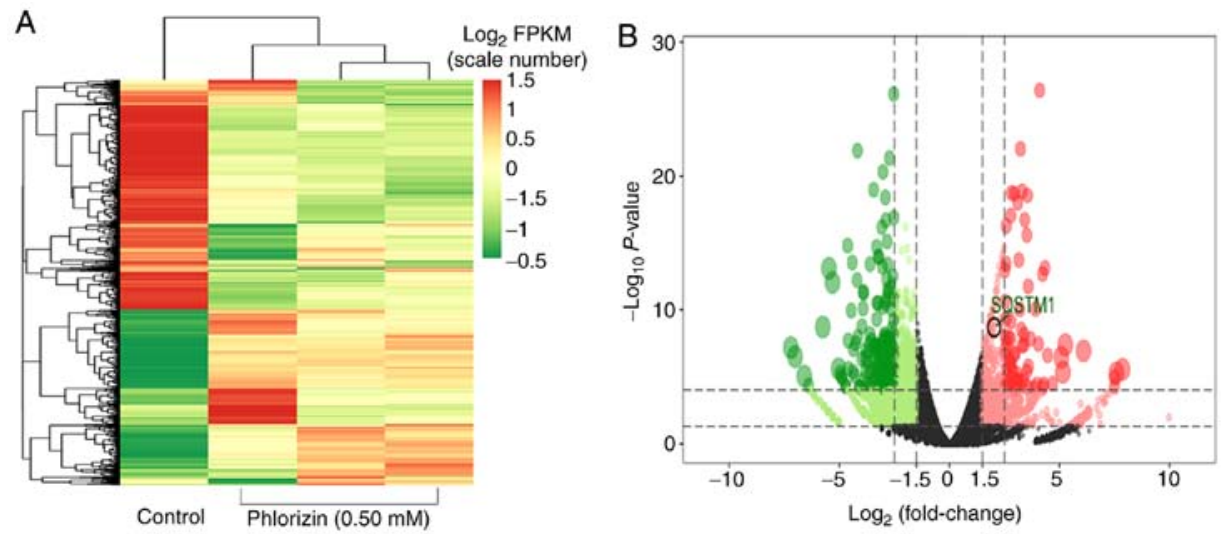

Figure 4. Changes in gene expression in the esophageal cancer cells treated with phlorizin. (A) The cluster heatmap of the DEGs and the green to red color scale indicates the value of $\log 2$ FPKM. (B) The volcano plot of the DEGs. The green and red indicates the down- and upregulated DEGs, respectively. DEGs, differentially expressed genes; FPKM, Fragments per kilobase of transcript per million mapped reads. 
A

GO:0000122 negative regulation of transcription from RNA polymerase II promoter GO:0045944 positive regulation of transcription from RNA polymerase II promoter. GO:0035914 skeletal muscle cell differentiation. GO:0032496 response to lipopolysaccharide. GO:0035994 response to muscle stretch. GO:0008285 negative regulation of cell proliferation. G0:0060707 trophoblast giant cell differentiation. GO:0038124 toll-like receptor TLR6:TLR2 signaling pathway . GO:0038123 roll-like receptor TLR1:TLR2 signaling pathway GO:0034146 toll-like receptor 5 signaling pathway . GO:0034166 toll-like receptor 10 signaling pathway . GO:0045080 positive regulation ol chemokine biosynthetic process. G0:0060021 palate development. GO:0002755 MyD88-dependent toll-like receptor signaling pathway . GO:0001077 RNA polymerase II core promoter proximal region sequence-specific GO:0000978 RNA polymerase II core promoter proximal region sequence-specific. GO:0071837 HMG box domain binding G0:0001078 RNA polymerase II core promoter proximal region sequence-speciñc G0:0005634 nucleus .
G0:00332561-kappaB/NF-kappaB complex.

в

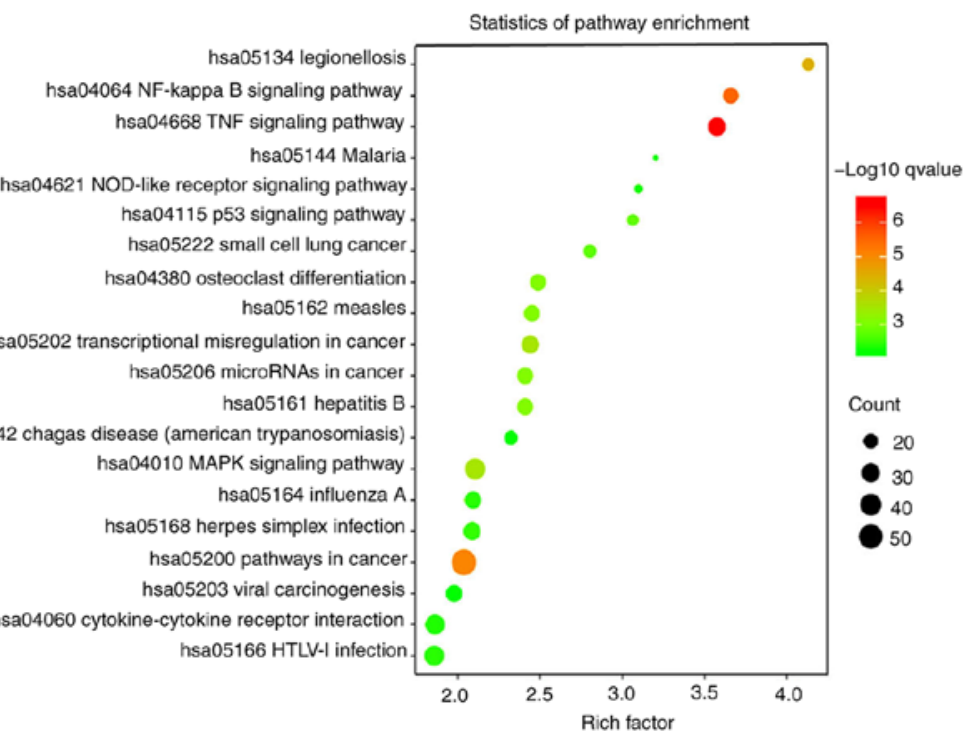

C

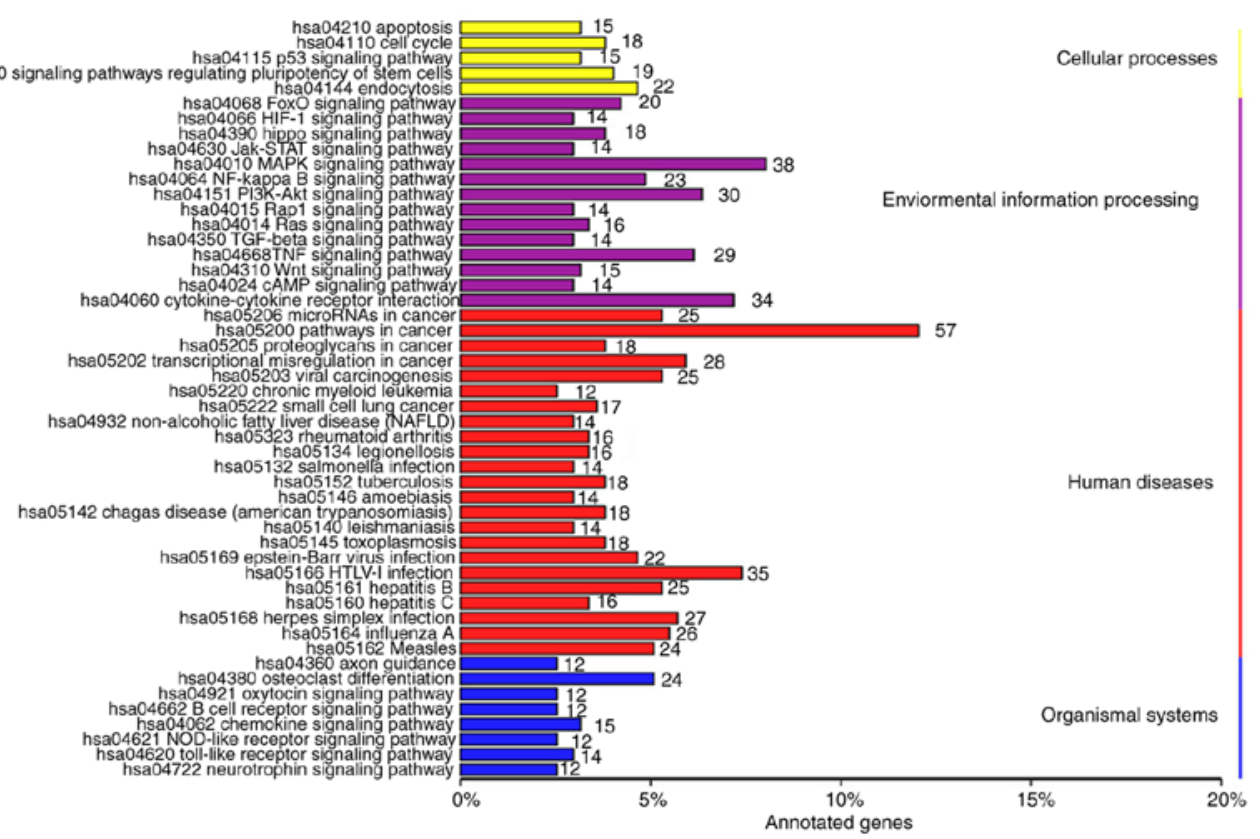

Figure 5. Functional and pathway enrichment analyses of the DEGs. (A) GO analysis of the DEGs. (B) The top 20 enriched pathways of the DEGs in KEGG. The green and red color indicates-log 10 (q value). (C) The top 50 KEGG pathways ranked by the number of enriched DEGs. GO, Gene Ontology; KEGG, Kyoto Encyclopedia of Genes and Genomes; DEGs, differentially expressed genes. 
A

KYSE450

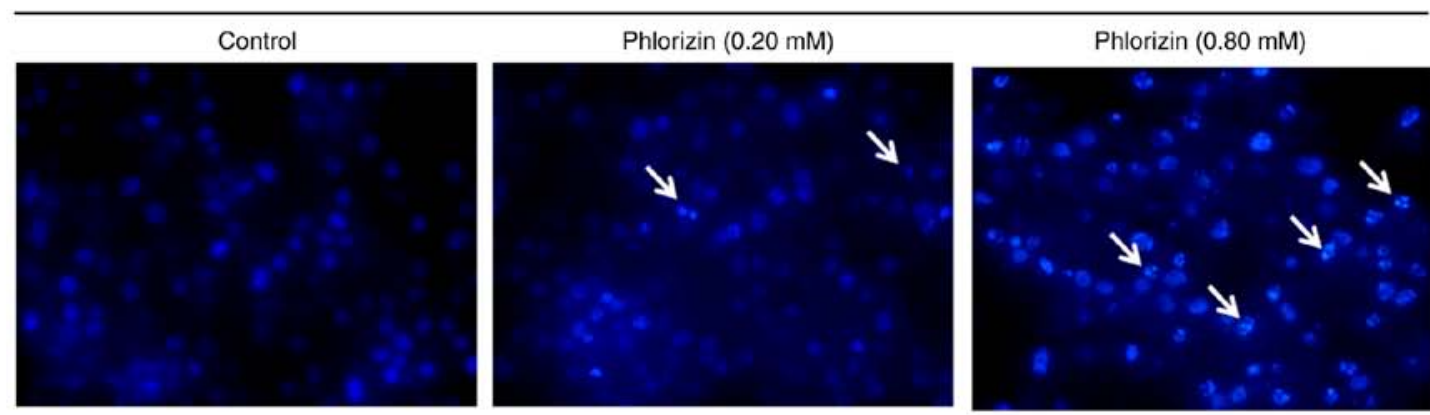

B

KYSE30

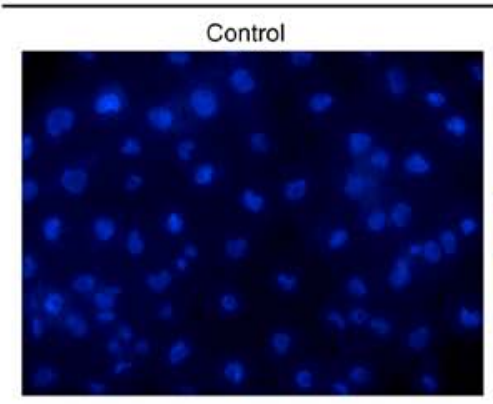

Phlorizin $(0.20 \mathrm{mM})$

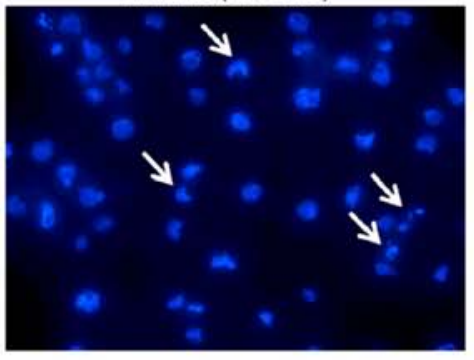

Phlorizin (0.80 mM)

C

KYSE 450

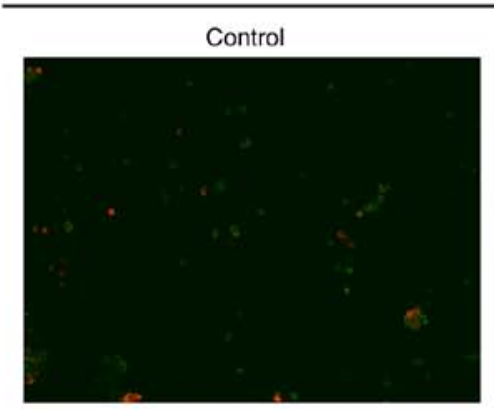

Phlorizin (0.20 mM)
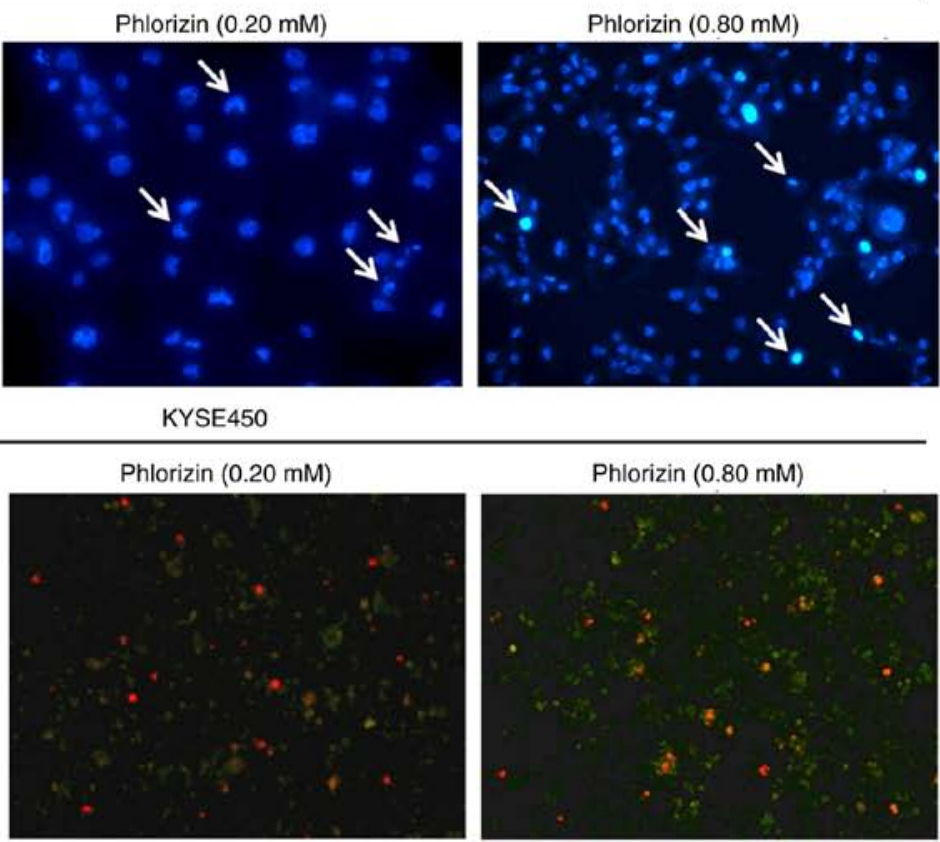

Phlorizin $(0.80 \mathrm{mM})$

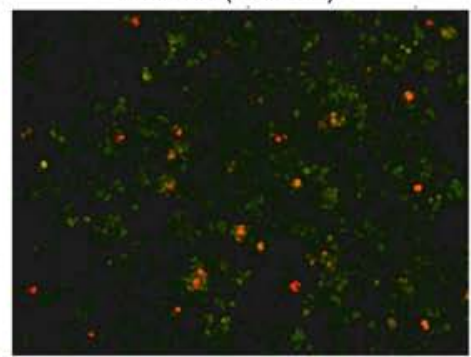

D

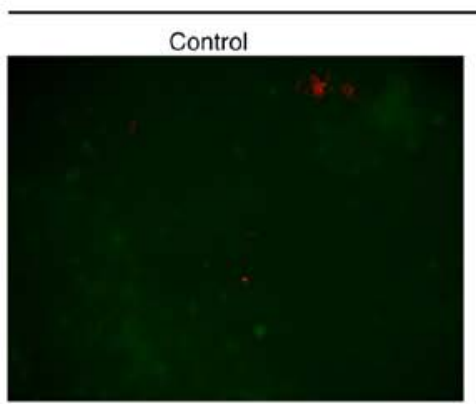

KYSE30

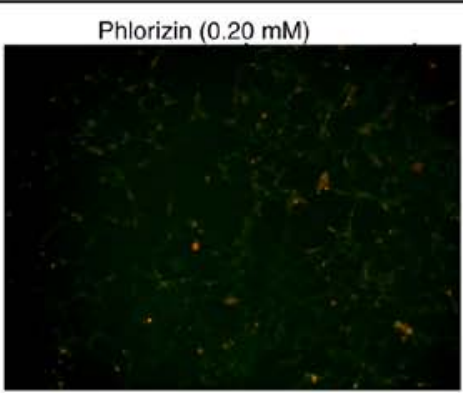

Phlorizin $(0.80 \mathrm{mM})$

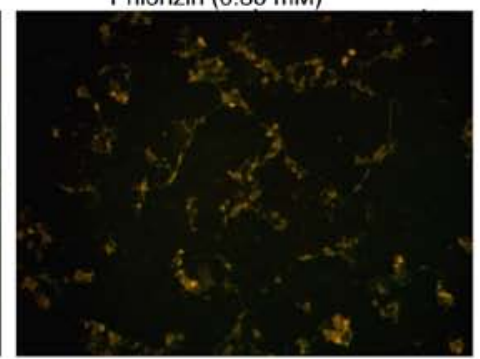

E
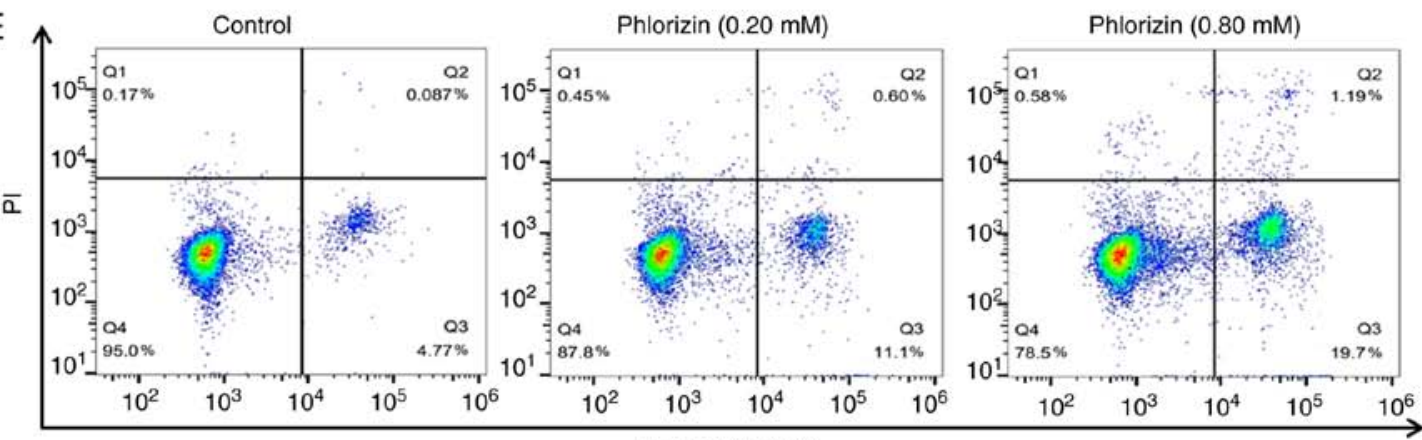

Annexin V-FITC

Figure 6. Phlorizin induces apoptosis of the esophageal cancer cells. Phlorizin induced apoptotic morphological changes in the (A) KYSE450 and (B) KYSE30 cells following treatment for $48 \mathrm{~h}$ were detected using Hoechst 3332 and the images were captured using a fluorescent microscope. Magnification, $\mathrm{x} 400$. Phlorizin induced apoptotic phase changes in the (C) KYSE450 and (D) KYSE30 cells following treatment for $48 \mathrm{~h}$ were detected using detected by Annexin V-FITC/PI staining. Magnification, x100. (E) Flow cytometry was used to detect the apoptosis-inducing ability of phlorizin in the KYSE30 cells. Each experiment was performed in triplicate. 
A

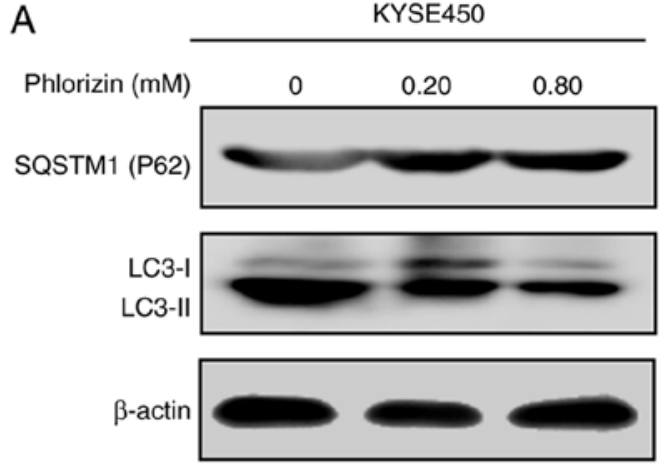

C

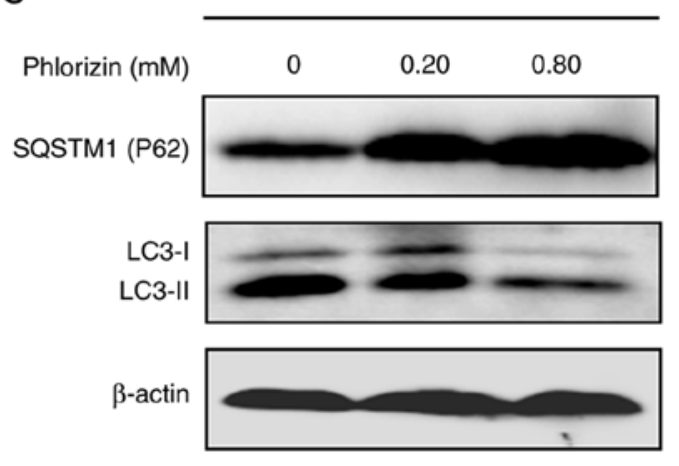

B

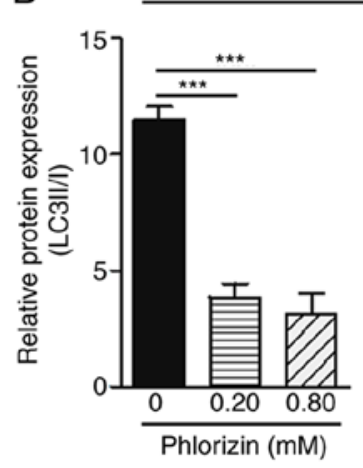

KYSE450

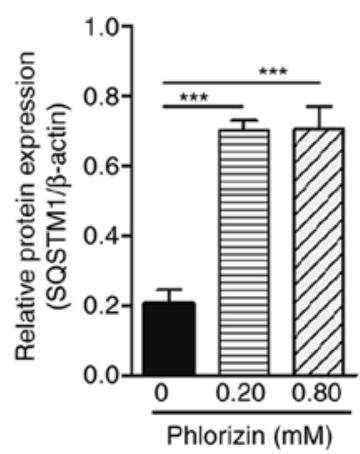

KYSE30

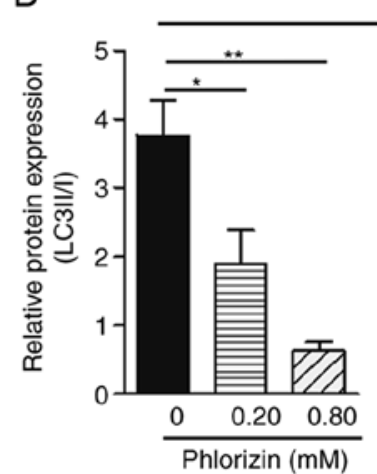

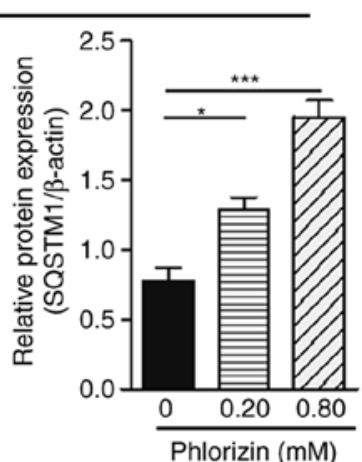

E

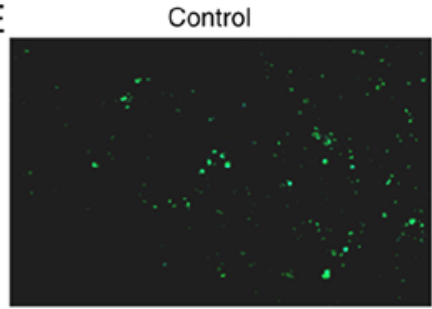

F

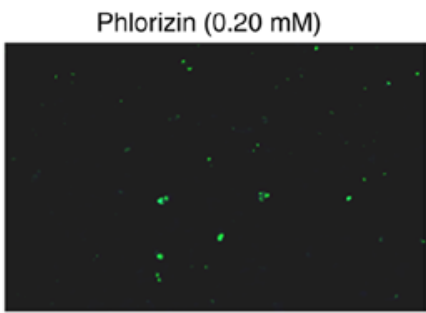

G

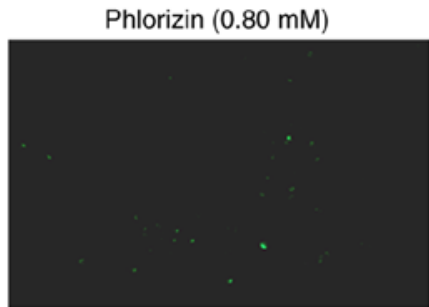

Figure 7. Phlorizin inhibits autophagy activation in esophageal cancer cells. (A) The protein expression level of P62/SQSTM1 and LC3II/I was determined using western blot analysis following treatment of the KYSE450 cells with phlorizin for $48 \mathrm{~h}$ and the results were (B) statistically analyzed using densitometry. (C) The protein expression level of P62/SQSTM1 and LC3II/I was determined using western blot analysis following treatment of the KYSE30 cells with phlorizin for $48 \mathrm{~h}$ and the results were (D) statistically analyzed using densitometry. The data are presented as the mean \pm SEM. (E-G) Autophagy was analyzed using MDC staining in the KYSE30 cells. Magnification, $\mathrm{x} 100 .{ }^{*} \mathrm{P}<0.05,{ }^{* *} \mathrm{P}<0.01$ and ${ }^{* * * *} \mathrm{P}<0.001$.

modifications. Most of the LC3-II proteins are distributed on the autophagosome membrane and a few are distributed on the membrane of the pre-autophagosome. LC3-II is an autophagy marker molecule, which reflects the autophagy activity of cells (41,45-47). P62/SQSTM1 is a ubiquitin-binding protein, which is expressed in numerous types of tissue and participates in a variety of signal transduction processes, as well as autophagy. P62/SQSTM1 is degraded by autophagy lysosome and is negatively associated with autophagy activity (44). To further verify the results, MDC-specific autophagy staining was performed and the results showed the inhibitory effect of phlorizin on autophagy. When cell energy is in crisis, autophagy can provide an alternative source of nutrition to the cells and prolong cell life. Autophagy can maintain energy homeostasis, which is crucial for the survival of mice during the early period of neonatal starvation (48). Autophagy is also involved in the maintenance of gene integrity by clearing the damage in response to metabolic stress, drug treatment and radiation damage. Therefore, inhibiting autophagy in cancer cells could improve the sensitivity of tumor cells to radiotherapy and chemotherapy (49).

In addition, numerous studies have shown that the JAK/STAT signaling pathway is important for growth, metastasis and apoptosis of esophageal cancer $(50,51)$. STAT3 has been reported to regulate the expression of different microRNAs, which targets autophagy-related genes. For example, STAT3 upregulated MIR17HG via the highly conserved STAT3 binding site in its promoter region, and family members of the MIR17HG cluster target the autophagy-related genes, ULK1, BECN1 and BCL2L11 (52-55). The results from the current study, suggested that phlorizin may exert an antitumor effect by inhibiting the JAK2/STAT3signaling pathway. However, the lack of using a JAK2/STAT3 agonist, antagonist or rescue experiments is a limitation to the present study, and the evidence supporting the effect of phlorizin on the JAK2/STAT3 signaling pathway is insufficient and further verification is required. According to the results from 
A

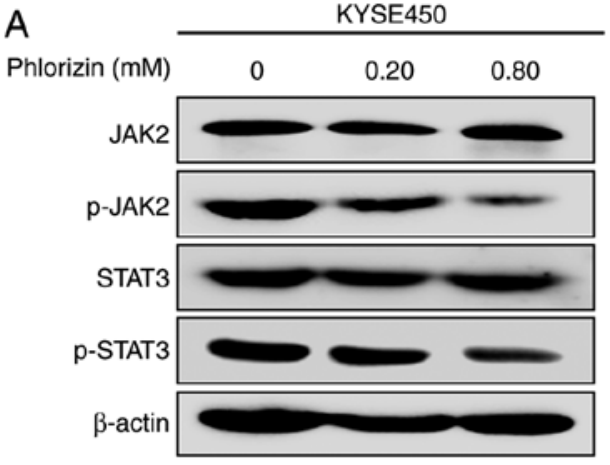

B

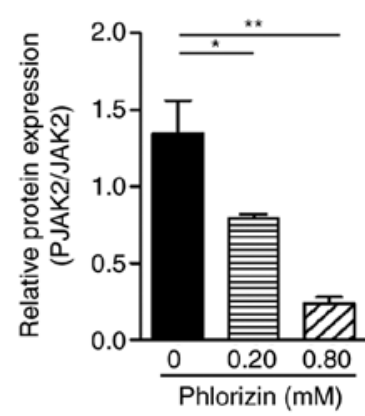

KYSE450

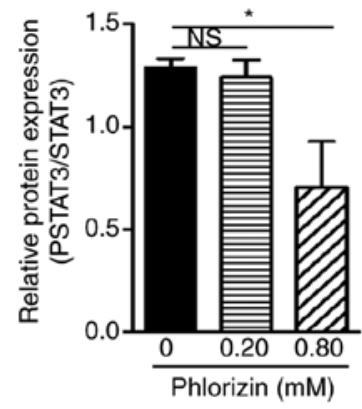

C

KYSE450
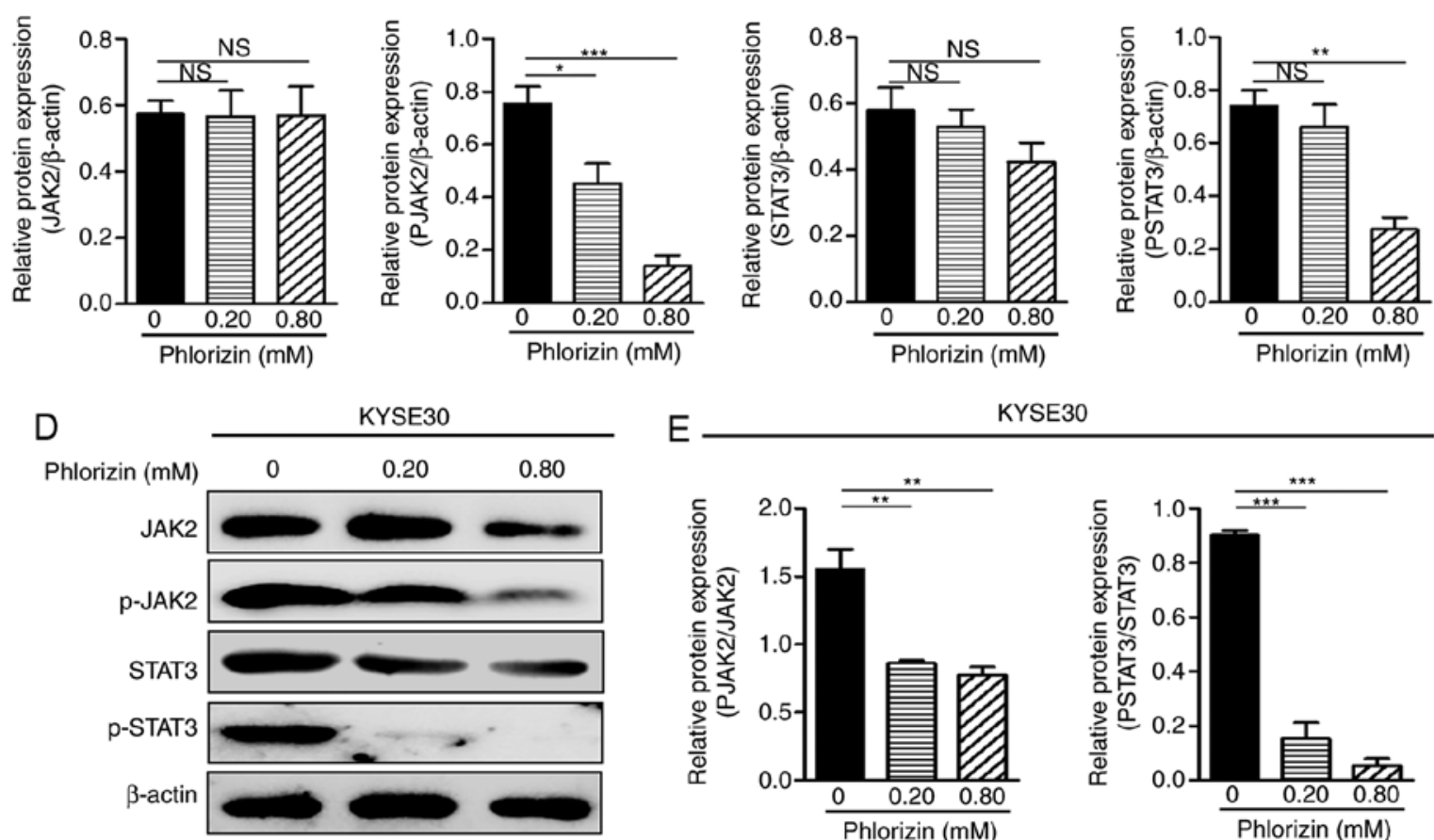

E

KYSE30
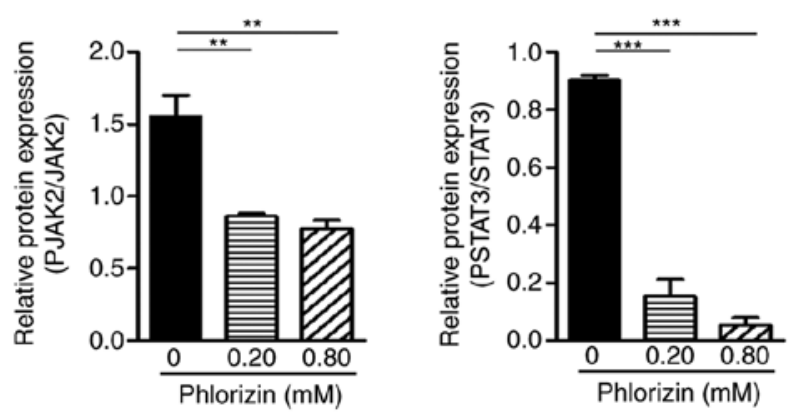

$\mathrm{F}$

KYSE30
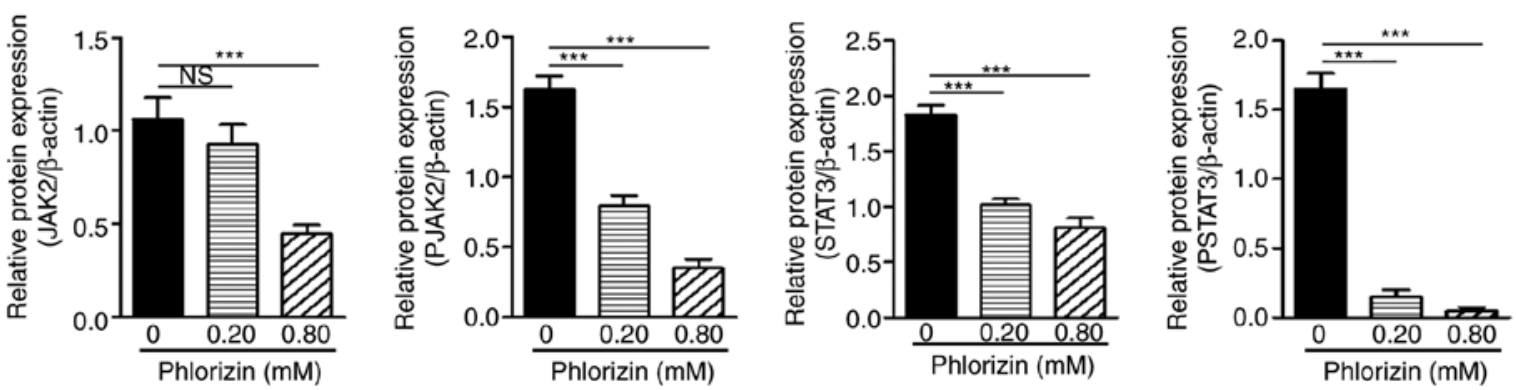

Figure 8. Phlorizin inhibits the activation of the JAK2/STAT3 signaling pathway. (A) The expression level of the proteins involved in the JAK2/STAT3 signaling pathway in the KYSE450 cells, following treatment with phlorizin for $48 \mathrm{~h}$, was analyzed using western blot analysis and the results were (B and C) statistically analyzed using densitometry. (D) The expression level of the proteins involved in the JAK2/STAT3 signaling pathway in the KYSE450 cells, following treatment with phlorizin for $48 \mathrm{~h}$, was analyzed using western blot analysis and the results were (E and F) statistically analyzed using densitometry. The results are presented as the mean $\pm \mathrm{SEM}$. ${ }^{*} \mathrm{P}<0.05,{ }^{* *} \mathrm{P}<0.01$ and ${ }^{* * *} \mathrm{P}<0.001$. p, phosphorylated; NS, not significant.

RNA-Seq, phlorizin might exert its effects by affecting other signaling pathways. This possibility remains to be verified. To further substantiate the results, in vivo experiments will also be performed to fully clarify the molecular mechanism of phlorizin in esophageal cancer. In addition, if a positive control group is designed, false negatives can also be ruled out.
In summary, the results from the present study revealed that phlorizin inhibited cell proliferation, invasion, migration, autophagy and activated apoptosis by antagonizing the JAK2/STAT3 signaling pathway. The finding will provide a theoretical basis and possibility for phlorizin as a natural food or pharmaceutical ingredient in the treatment of esophageal cancer. 


\section{Acknowledgements}

Not applicable.

\section{Funding}

This study was funded by the National Natural Science Foundation of China (grant no. 81272613), Key Project of Natural Science Foundation of Hebei province of China (grant no. H2017209233), Hebei High-level Talent Cultivation Plan in University (grant no. GCC2014050) and the Graduate Student Innovation Fund of North China University of Science and Technology (grant no. 2019S12).

\section{Availability of data and materials}

The datasets used and/or analyzed during the study are available from the corresponding author upon reasonable request. Sequencing data generated for this study have been submitted to the NCBI Sequence Read Archive (SRA; http://www.ncbi. nlm.nih.gov/sra) and the accession number is PRJNA685263.

\section{Authors' contributions}

$\mathrm{XZ}, \mathrm{ZJ}$ and $\mathrm{ZX}$ designed the experiments. ZJ, YX, HW, $\mathrm{ZW}, \mathrm{AL}$ and $\mathrm{ZL}$ performed the experiments. ZJ, ZY and ZZ performed the analysis and interpretation of the data. $Z J$ and $\mathrm{ZY}$ drafted the manuscript. $\mathrm{XZ}$ and $\mathrm{ZZ}$ revised the manuscript. $\mathrm{ZJ}$ prepared the figures. XZ provided financial support and supervised the project. All authors reviewed and approved the final version of the manuscript.

\section{Ethics approval and consent to participate}

Not applicable.

\section{Patient consent for publication}

Not applicable.

\section{Competing interests}

The authors declare that they have no competing interests.

\section{References}

1. Lin Y, Totsuka Y, He Y, Kikuchi S, Qiao Y, Ueda J, Wei W, Inoue $\mathrm{M}$ and Tanaka $\mathrm{H}$ : Epidemiology of esophageal cancer in Japan and China. J Epidemiol 23: 233-242, 2013.

2. Malhotra GK, Yanala U, Ravipati A, Follet M, Vijayakumar M and Are C: Global trends in esophageal cancer. J Surg Oncol 115: 564-579, 2017.

3. Zhang Y: Epidemiology of esophageal cancer. World J Gastroenterol 19: 5598-5606, 2013.

4. Bray F, Ferlay J, Soerjomataram I, Siegel RL, Torre LA and Jemal A: Global cancer statistics 2018: GLOBOCAN estimates of incidence and mortality worldwide for 36 cancers in 185 countries. CA Cancer J Clin 68: 394-424, 2018.

5. Greally $\mathrm{M}$ and Ilson DH: Neoadjuvant therapy for esophageal cancer: Who, when, and what? Cancer 124: 4276-4278, 2018

6. Semenkovich TR, Subramanian M, Yan Y, Hofstetter WL, Correa AM, Cassivi SD, Inra ML, Stiles BM, Altorki NK, Chang AC, et al: Adjuvant therapy for node-positive esophageal cancer after induction and surgery: A multisite study. Ann Thorac Surg 108: 828-836, 2019.
7. Borggreve AS, Kingma BF, Ruurda JP and van Hillegersberg R; Dutch Upper G.I. Cancer Audit (DUCA) group: Safety and feasibility of minimally invasive surgical interventions for esophageal and gastric cancer in the acute setting: A nationwide cohort study. Surg Endosc 35: 1219-1229, 2021.

8. Worrell SG, Bachman KC, Sarode AL, Perry Y, Linden PA and Towe CW: Minimally invasive esophagectomy is associated with superior survival, lymphadenectomy and surgical margins: Propensity matched analysis of the National Cancer Database. Dis Esophagus 33: doaa017, 2020.

9. Deng W, Yang J, Ni W, Li C, Chang X, Han W, Zhou Z, Chen D, Feng Q, Liang J, et al: Postoperative radiotherapy in pathological T2-3N0M0 thoracic esophageal squamous cell carcinoma: Interim report of a prospective, phase III, randomized controlled study. Oncologist 25: e701-e708, 2020.

10. Miller KD, Siegel RL, Lin CC, Mariotto AB, Kramer JL, Rowland JH, Stein KD, Alteri R and Jemal A: Cancer treatment and survivorship statistics, 2016. CA Cancer J Clin 66: 271-289, 2016.

11. Cragg GM and Pezzuto JM: Natural products as a vital source for the discovery of cancer chemotherapeutic and chemopreventive agents. Med Princ Pract 25 (Suppl 2): S41-S59, 2016.

12. Sanders K, Moran Z, Shi Z, Paul R and Greenlee H: Natural products for cancer prevention: Clinical Update 2016. Semin Oncol Nurs 32: 215-240, 2016.

13. Ma J, Hu X, Liao C, Xiao H, Zhu Q, Li Y, Liu Z, Tao A, He Z, $\mathrm{Xu} \mathrm{C}$ and Zheng $\mathrm{K}$ : Gypenoside $\mathrm{L}$ inhibits proliferation of liver and esophageal cancer cells by inducing senescence. Molecules 24: 1054, 2019.

14. Jiang JH, Pi J, Jin H, Yang F and Cai JY: Chinese herb medicine matrine induce apoptosis in human esophageal squamous cancer KYSE-150 cells through increasing reactive oxygen species and inhibiting mitochondrial function. Pathol Res Pract 214: 691-699, 2018.

15. Sun Y, Li W and Liu Z: Preparative isolation, quantification and antioxidant activity of dihydrochalcones from Sweet Tea (Lithocarpus polystachyus Rehd.). J Chromatogr B Analyt Technol Biomed Life Sci 1002: 372-378, 2015.

16. Hou SZ, Chen SX, Huang S, Jiang DX, Zhou CJ, Chen CQ, Liang YM and Lai XP: The hypoglycemic activity of Lithocarpus polystachyus Rehd. leaves in the experimental hyperglycemic rats. J Ethnopharmacol 138: 142-149, 2011.

17. Gosch C,Halbwirth $\mathrm{H}$ and Stich K: Phloridzin: Biosynthesis, distribution and physiological relevance in plants. Phytochemistry 71: 838-843, 2010.

18. Panayotova-Heiermann M, Loo DD and Wright EM: Kinetics of steady-state currents and charge movements associated with the rat Na+/glucose cotransporter. J Biol Chem 270: 27099-27105, 1995.

19. Ehrenkranz JR, Lewis NG, Kahn CR and Roth J: Phlorizin: A review. Diabetes Metab Res Rev 21: 31-38, 2005.

20. Wang H, Cheng J, Wang H, Wang M, Zhao J and Wu Z: Protective effect of apple phlorizin on hydrogen peroxide-induced cell damage in HepG2 cells. J Food Biochem 43: e13052, 2019.

21. Wang Z, Gao Z, Wang A, Jia L, Zhang X, Fang M, Yi K, Li Q and $\mathrm{Hu} \mathrm{H}$ : Comparative oral and intravenous pharmacokinetics of phlorizin in rats having type 2 diabetes and in normal rats based on phase II metabolism. Food Funct 10: 1582-1594, 2019.

22. Park J, Kwon O, Cho SY, Cho MC, Paick JS and Kim SW: Comparison of improving effects for diabetic erectile dysfunction according to the anti-glycemic agents: Phlorizin and insulin. World J Mens Health 37: 210-218, 2019.

23. Trapnell C, Pachter L and Salzberg SL: TopHat: Discovering splice junctions with RNA-Seq. Bioinformatics 25: 1105-1111, 2009.

24. Ghosh S and Chan CK: Analysis of RNA-Seq data using TopHat and cufflinks. Methods Mol Biol 1374: 339-361, 2016.

25. Fan J, Ren D, Wang J, Liu X, Zhang H, Wu M and Yang G: Bruceine D induces lung cancer cell apoptosis and autophagy via the ROS/MAPK signaling pathway in vitro and in vivo. Cell Death Dis 11: 126, 2020.

26. Zhou YY, Li Y, Jiang WQ and Zhou LF: MAPK/JNK signalling: A potential autophagy regulation pathway. Biosci Rep 35: e00199, 2015 .

27. Goruppi S, Jo SH, Laszlo C, Clocchiatti A, Neel V and Dotto GP: Autophagy controls CSL/RBPJא stability through a p62/SQSTM1-dependent mechanism. Cell Rep 24: 3108-3114.e4, 2018.

28. Lamark T, Svenning S and Johansen T: Regulation of selective autophagy: The p62/SQSTM1 paradigm. Essays Biochem 61: 609-624, 2017 
29. Lee M, Nam HY, Kang HB, Lee WH, Lee GH, Sung GJ, Han MW, Cho KJ, Chang EJ, Choi KC, et al: Epigenetic regulation of p62/SQSTM1 overcomes the radioresistance of head and neck cancer cells via autophagy-dependent senescence induction. Cell Death Dis 12: 250, 2021.

30. Lu Z, Lu C, Li C, Jiao Y, Li Y and Zhang G: Dracorhodin perchlorate induces apoptosis and $\mathrm{G} 2 / \mathrm{M}$ cell cycle arrest in human esophageal squamous cell carcinoma through inhibition of the JAK2/STAT3 and AKT/FOXO3a pathways. Mol Med Rep 20: 2091-2100, 2019.

31. Song M, Yoon G, Choi JS, Kim E, Liu X, Oh HN, Chae JI, Lee MH and Shim JH: Janus kinase 2 inhibition by Licochalcone B suppresses esophageal squamous cell carcinoma growth. Phytother Res 34: 2032-2043, 2020.

32. Wang Y, Zhou P, Qin S, Xu D, Liu Y, Fu W, Ruan B, Zhang L, Zhang Y, Wang X, et al: The curcumin analogs 2-pyridyl cyclohexanone induce apoptosis via inhibition of the JAK2-STAT3 pathway in human esophageal squamous cell carcinoma cells. Front Pharmacol 9: 820, 2018.

33. Gali-Muhtasib H, Hmadi R, Kareh M, Tohme R and Darwiche N: Cell death mechanisms of plant-derived anticancer drugs: Beyond apoptosis. Apoptosis 20: 1531-1562, 2015.

34. Ammoury C, Younes M, El Khoury M, Hodroj MH, Haykal T, Nasr P, Sily M, Taleb RI, Sarkis R, Khalife R and Rizk S: The pro-apoptotic effect of a Terpene-rich Annona cherimola leaf extract on leukemic cell lines. BMC Complement Altern Med 19: 365, 2019.

35. Chen Y, Liu J, Geng S, Liu Y, Ma H, Zheng J, Liu B and Liang G: Lipase-catalyzed synthesis mechanism of tri-acetylated phloridzin and its antiproliferative activity against HepG2 cancer cells. Food Chem 277: 186-194, 2019.

36. Qin X, Xing YF, Zhou Z and Yao Y: Dihydrochalcone compounds isolated from crabapple leaves showed anticancer effects on human cancer cell lines. Molecules 20: 21193-21203, 2015.

37. Ma C, Zhu L, Wang J, He H, Chang X, Gao J, Shumin W and Yan T: Anti-inflammatory effects of water extract of Taraxacum mongolicum hand.-Mazz on lipopolysaccharide-induced inflammation in acute lung injury by suppressing PI3K/Akt/mTOR signaling pathway. J Ethnopharmacol 168: 349-355, 2015.

38. Deng X, Liu J, Liu L, Sun X, Huang J and Dong J: Drp1-mediated mitochondrial fission contributes to baicalein-induced apoptosis and autophagy in lung cancer via activation of AMPK signaling pathway. Int J Biol Sci 16: 1403-1416, 2020.

39. Liao B, Sun Q, Yuan Y, Yin Y, Qiao J and Jiang P: Histone deacetylase inhibitor MGCD0103 causes cell cycle arrest, apoptosis, and autophagy in liver cancer cells. J Cancer 11: 1915-1926, 2020 .

40. Liu W, Chai Y, Hu L, Wang J, Pan X, Yuan H, Zhao Z, Song Y and Zhang Y: Polyphyllin VI induces apoptosis and autophagy via reactive oxygen species mediated JNK and P38 activation in glioma. Onco Targets Ther 13: 2275-2288, 2020.

41. Kabeya Y, Mizushima N, Ueno T, Yamamoto A, Kirisako T, Noda T, Kominami E, Ohsumi Y and Yoshimori T: LC3, a mammalian homologue of yeast Apg8p, is localized in autophagosome membranes after processing. EMBO J 19: 5720-5728, 2000 .
42. Mizushima $\mathrm{N}$ and Yoshimori T: How to interpret LC3 immunoblotting. Autophagy 3: 542-545, 2007.

43. Yorimitsu T and Klionsky DJ: Autophagy: Molecular machinery for self-eating. Cell Death Differ 12 (Suppl 2): S1542-S1552, 2005.

44. Lin X, Li S, Zhao Y, Ma X, Zhang K, He X and Wang Z Interaction domains of p62: A bridge between p62 and selective autophagy. DNA Cell Biol 32: 220-227, 2013.

45. Bansal M, Moharir SC and Swarup G: Autophagy receptor optineurin promotes autophagosome formation by potentiating LC3-II production and phagophore maturation. Commun Integ Biol 11: 1-4, 2018.

46. do Nascimento-Neto LG, Cabral MG, Carneiro RF, Silva Z, Arruda FVS, Nagano CS, Fernandes AR, Sampaio AH, Teixeira EH and Videira PA: Halilectin-3, a lectin from the marine sponge haliclona caerulea, induces apoptosis and autophagy in human breast cancer MCF7 cells through caspase-9 pathway and LC3-II protein expression. Anticancer Agents Med Chem 18: 521-528, 2018.

47. Zhang N, Li L, Wang J, Cao M, Liu G, Xie G, Yang Z and Li Y: Study of autophagy-related protein light chain 3 (LC3)-II expression levels in thyroid diseases. Biomed Pharmacother 69: 306-310, 2015.

48. Kuma A, Hatano M, Matsui M, Yamamoto A, Nakaya H, Yoshimori T, Ohsumi Y, Tokuhisa T and Mizushima N: The role of autophagy during the early neonatal starvation period. Nature 432: 1032-1036, 2004.

49. Guo JY, Xia B and White E: Autophagy-mediated tumor promotion. Cell 155: 1216-1219, 2013.

50. Timme S, Ihde S, Fichter CD, Waehle V, Bogatyreva L, Atanasov K,KohlerI,Schöpflin A,GeddertH,FallerG,etal:STAT3 expression, activity and functional consequences of STAT3 inhibition in esophageal squamous cell carcinomas and Barrett's adenocarcinomas. Oncogene 33: 3256-3266, 2014.

51. Liu JR, Wu WJ, Liu SX, Zuo LF, Wang Y, Yang JZ and Nan YM: Nimesulide inhibits the growth of human esophageal carcinoma cells by inactivating the JAK2/STAT 3 pathway. Pathol Res Pract 211: 426-434, 2015

52. Brock M, Trenkmann M, Gay RE, Michel BA, Gay S, Fischler M, Ulrich S, Speich R and Huber LC: Interleukin-6 modulates the expression of the bone morphogenic protein receptor type II through a novel STAT3-microRNA cluster 17/92 pathway. Circ Res 104: 1184-1191, 2009.

53. Wu H, Wang F, Hu S, Yin C, Li X, Zhao S, Wang J and Yan X: MiR-20a and miR-106b negatively regulate autophagy induced by leucine deprivation via suppression of ULK1 expression in C2C12 myoblasts. Cell Signal 24: 2179-2186, 2012.

54. Chatterjee A, Chattopadhyay D and Chakrabarti G: miR-17-5p downregulation contributes to paclitaxel resistance of lung cancer cells through altering beclin1 expression. PLoS One 9: e95716, 2014.

55. Spaccarotella E, Pellegrino E, Ferracin M, Ferreri C, Cuccuru G, Liu C, Iqbal J, Cantarella D, Taulli R, Provero P, et al: STAT3-mediated activation of microRNA cluster 17 92 promotes proliferation and survival of ALK-positive anaplastic large cell lymphoma. Haematologica 99: 116-124, 2014.

This work is licensed under a Creative Commons

Attribution-NonCommercial-NoDerivatives 4.0 International (CC BY-NC-ND 4.0) License. 